\title{
How Dissociation of Carboxylic Acid Groups in a Weak Polyelectrolyte Brush Depend on Their Distance from the Substrate
}

\author{
Ehtiati, Koosha; Moghaddam, Saeed Zajforoushan; Daugaard, Anders Egede; Thormann, Esben
}

Published in:

Langmuir

Link to article, DOI:

10.1021/acs.langmuir.9b03537

Publication date:

2020

Document Version

Publisher's PDF, also known as Version of record

Link back to DTU Orbit

Citation (APA):

Ehtiati, K., Moghaddam, S. Z., Daugaard, A. E., \& Thormann, E. (2020). How Dissociation of Carboxylic Acid Groups in a Weak Polyelectrolyte Brush Depend on Their Distance from the Substrate. Langmuir, 36(9), 23392348. https://doi.org/10.1021/acs.langmuir.9b03537

\section{General rights}

Copyright and moral rights for the publications made accessible in the public portal are retained by the authors and/or other copyright owners and it is a condition of accessing publications that users recognise and abide by the legal requirements associated with these rights.

- Users may download and print one copy of any publication from the public portal for the purpose of private study or research.

- You may not further distribute the material or use it for any profit-making activity or commercial gain

- You may freely distribute the URL identifying the publication in the public portal 


\title{
How Dissociation of Carboxylic Acid Groups in a Weak Polyelectrolyte Brush Depend on Their Distance from the Substrate
}

\author{
Koosha Ehtiati, Saeed Z. Moghaddam, Anders E. Daugaard, and Esben Thormann* \\ Cite This: Langmuir 2020, 36, 2339-2348 \\ Read Online
}

ABSTRACT: A weak polyelectrolyte brush is composed of a layer of polyacids or polybases grafted by one end of their chains to a substrate surface. For such brush layers immersed in an aqueous solution, the dissociation behavior of the acidic or basic groups and the structural and physical properties of the brush layer will thus be strongly dependent on the environmental conditions. For a polyacid brush layer consisting of, e.g., poly(acrylic acid), this means that the chains in the brush layer will be charged at high $\mathrm{pH}$ and uncharged at low $\mathrm{pH}$. However, theoretical scaling laws not only foresee the structural changes occurring in response to the $\mathrm{pH}$-induced dissociation behavior but also how the dissociation behavior of the brush layer depends on the ionic strength of the aqueous solution and the density of acidic groups within the brush layer. We have herein employed spectroscopic ellipsometry and a quartz crystal microbalance with dissipation monitoring (QCM-D) to experimentally evaluate the theoretically predicted dissociation and structural behavior of PAA brushes. Spectroscopic ellipsometry allows us to study the brush thickness as a function of $\mathrm{pH}$ and ionic strength, while QCM-D gives us an opportunity to investigate the swelling behavior of PAA brushes at various penetration depths of propagating acoustic waves. Our studies show that the dissociation degree of the carboxylic acid groups in a PAA brush increases with increasing distance from the substrate. Moreover, the ionic strength enhances carboxylic acid dissociation, such that a higher ionic strength leads to a narrower distribution and higher average dissociation degree. In conclusion, our results provide an experimental verification of the theoretically predicted gradient in the degree of dissociation of the acid groups in weak polyacid brush layers and shows that at a $\mathrm{pH}$ value equal to approximately the average $\mathrm{p} K_{\mathrm{a}}$ value of the brush, the state of the acid groups varies from being almost uncharged to almost fully dissociated depending on the ionic strength and vertical position in the brush.

\section{INTRODUCTION}

Since the first theoretical description of polymer brush layers by Alexander and de Gennes, ${ }^{1,2}$ such molecular structures have attracted major interest due to their simple nature and very complex structural behavior. From a theoretical perspective, polymer brush layers constitute attractive systems with welldefined fixed conditions, such as monomeric chemistry, grafting density, chain contour length, and some well-defined system variables such as solvent quality, ionic strength, and $\mathrm{pH}$, which allow for predictions about the polymer brush structure and, in particular, the brush height. To this end, a number of scaling relations between the polymer brush height and the fixed conditions and system variables have been derived for brush layers of neutral polymers, strong polyelectrolytes, and weak polyelectrolytes. ${ }^{1-10}$ From an experimental perspective, the interest in these structures has been two-fold. First, experimental tests of the theoretical scaling relations are attractive because variations in some starting conditions, i.e., monomeric chemistry, grafting density, and polymer contour length, can be controlled during brush layer preparation, while variables such as solvent quality, ionic strength, and $\mathrm{pH}$ can be controlled after brush layer preparation. ${ }^{11-19}$ Second, polymer brush layers constitute novel functionalities such as low friction, ${ }^{20-22}$ high loadbearing capacity, ${ }^{23,24}$ antifouling behavior, ${ }^{25-27}$ and responsive nature ${ }^{28-31}$ and have many potential applications. $^{32-34}$

Weak polyelectrolyte brushes, in general, demonstrate a more complex structural behavior than layers composed of strong polyelectrolytes. Starting from a simple monomeric structure with an acidic or basic group and a well-defined $\mathrm{p} K_{\mathrm{a}}$ value, the situation already becomes more complicated when these groups are constrained to the polymer backbone where the dissociation of a specific group depends not only on the solution $\mathrm{pH}$ but also on the state of neighboring dissociable groups and the local electrostatic environment. However, the most complex situation is found in the brush layer structure, where the degree of dissociation will depend on the solution

Received: November 13, 2019

Revised: January 13, 2020

Published: February 18, 2020 
$\mathrm{pH}$, the concentration of added salt, and the local polymer concentration.

Experimental investigation of the degree of dissociation in a weak polyelectrolyte brush layer is not as straightforward as for weak polyelectrolytes in solution, where the solution can be titrated by acidic or basic solutions and the $\mathrm{pH}$ can be monitored. For polymer brush layers, one way to obtain direct information about the degree of dissociation is via a spectroscopic approach, for example, grazing-angle reflectance (GAR) Fourier-transform infrared spectroscopy (FTIR). However, so far this has not been done directly in a $\mathrm{pH}$ adjusted solution but in a dry state after the chemical structure was quenched at a given $\mathrm{pH}$ value. ${ }^{35}$ Thus, as consequence of the difficulties in obtaining direct chemical information for weak polyelectrolyte brush layer at the relevant experimental condition, it has been common to study how different physical parameters like brush wettability, brush height, or viscoelasticity using techniques like contact angle measurement, ${ }^{35,36}$ ellipsometry, ${ }^{13,18,19,37-43}$ neutron reflectometry, ${ }^{44,45}$ or QCM$\mathrm{D}^{43,46-48}$ varies as a function of $\mathrm{pH}$. A drawback of such an approach is that one cannot automatically ensure a $1: 1$ correspondence between the change in dissociation and the physical response to the change in dissociation. This, for example, means that the midpoint of a structural change, which occurs in response to the change in the degree of dissociation, does not necessarily correspond to the true $\mathrm{p} K_{\mathrm{a}}$ value. For that reason, in this work we will refer to such a value as the "apparent $\mathrm{p} K_{\mathrm{a}}$ value".

For both direct and indirect methods, in addition to note above, one has to be aware that the measured signal does not necessarily represent a response to the dissociation behavior of all acidic or basic groups in the brush layer. Instead, such measurements reflect the behavior of either the groups in the outer part of the brush layer (contact angle measurements) or a (differently) weighted average of all the groups in the brush layer (typically all other techniques). While this information might be sufficient if one aims to test the established scaling relations or wants to apply the brush as a stimuli responsive surface, it does not reveal full information about the dissociation behavior in a weak polyelectrolyte brush layer. In particular, such measurements do not carry any information about local variations in the dissociation behavior related to an uneven vertical polymer density profile through the brush layer. To this end, experimental studies have demonstrated an uneven polymer density profile in neutral and charged polymer brushes, ${ }^{45,49-51}$ confirmed by theoretical studies, $4,52-54$ and variation of this profile with $\mathrm{pH}$, salt, and temperature for stimuli-responsive brushes. ${ }^{45,55}$ This means that the polymer density indeed changes with the vertical distance from the grafting points. Dissociation of acid groups in a weak polyelectrolyte brush, on the other hand, depends on the polymer density ${ }^{9}$ and on the vertical position in the brush, consequently. In this regard theoretical modeling has shown that at a fixed $\mathrm{pH}$ value the degree of dissociation generally increases with increasing distance from the surface grafting point. ${ }^{6,56,57}$ Further, a comparison between the apparent $\mathrm{pK} K_{\mathrm{a}}$ values obtained by contact angle measurements and grazingangle reflectance FTIR demonstrate a higher degree of dissociation at the outer part of the brush layer compared to the average degree of dissociation. ${ }^{35}$ However, more detailed insight into the dissociation behavior of weak polyelectrolyte brush layers has so far been experimentally inaccessible.
In this work, we use ellipsometry and QCM-D for indirect studies of the dissociation behavior of poly(acrylic acid) (PAA) brush layers as a function of $\mathrm{pH}$ and ionic strength. To this end, ellipsometry shows variations in the optical properties and the thickness of the brush as a function of increasing $\mathrm{pH}$, which we use to estimate an average apparent $\mathrm{p} K_{\mathrm{a}}$ value for the PAA brush. On the other hand, the quartz crystal microbalance with dissipation (QCM-D) technique is an acoustic method that can be used to measure the viscoelastic properties of the brush layer; this method is extremely sensitive to conformation changes that influence the water content of the layer or its dissipative behavior. ${ }^{43,46} \mathrm{We}$ are, however, focused on the fact that the propagations of the shear acoustic waves representing the different overtone harmonics have varying magnitudes. ${ }^{5-60}$ This explicitly means that higher overtone harmonics exhibit shorter decay lengths than lower overtone harmonics and that the various overtone harmonics sense dissimilar penetration depths for the brush layer. Here, we utilize this knowledge as an indirect tool to probe the dissociation behavior as a function of the vertical position in the brush layer.

\section{EXPERIMENTAL SECTION}

Materials. Dichloromethane, 2-bromoisobutyryl bromide, triethylamine, toluene, $N, N$-dimethylformamide (DMF), $N, N, N^{\prime}, N^{\prime}, N^{\prime \prime}$ pentamethyldiethylenetriamine (PMDETA), tert-butyl acrylate (tBA), ethyl $\alpha$-bromoisobutyrate (EBiB), copper(II) sulfate pentahydrate, sodium sulfite, and trifluoroacetic acid were obtained from Sigma-Aldrich and used as received. Copper(II) bromide $\left(\mathrm{CuBr}_{2}\right)$ and (3-aminopropyl)triethoxysilane (APTES) were purchased from Riedel-de Haën and the Tokyo Chemical Industry, respectively. Ultrapure water with a resistance of $18.2 \mathrm{M} \Omega \cdot \mathrm{cm}$ (Sartorius Arium Pro) was used for the preparation of all the aqueous solutions. Solutions for ellipsometry experiments were prepared using ultrapure water and $\mathrm{NaCl}$ to adjust the ionic strength. $\mathrm{HCl}$ and $\mathrm{NaOH}$ were used to adjust the $\mathrm{pH}$ values.

Synthesis of Poly(acrylic acid) Brushes on Solid Surfaces. Thermally oxidized silicon wafers (Wafer Net, USA) and a QCM-D sensor (QSX335, Biolin Scientific, Gothenburg, Sweden) were used to prepare the PAA brushes. Prior to functionalization, the silicon wafers were rinsed with acetone, ethanol, and deionized water three times. The surfaces were subsequently plasma-cleaned (Harrick Plasma) for 3 min under $500 \mathrm{mT}$ orr water vapor to produce hydroxyl groups on the wafer surfaces. Vapor deposition was applied to functionalize wafer surfaces with amine groups; the surfaces were kept in a desiccator, where a solution of APTES and toluene (volume ratio: 1:1) had been placed for $24 \mathrm{~h}$. Afterward, the wafer surfaces were washed with toluene, ethanol, and acetone and dried under a stream of argon. The QCM-D sensor and the silicon wafer were placed in the same reaction mixture in every step. A Teflon fixture was used to cover the backside of the QCM-D sensor in the reaction mixture. To graft the initiators onto the surface, functionalized surfaces were placed into a mixture of dichloromethane $(40 \mathrm{~mL})$ and triethylamine $(1.9 \mathrm{~g}, 19 \mathrm{mmol})$ at $0{ }^{\circ} \mathrm{C}$; then, 2-bromoisobutyryl bromide $(3.7 \mathrm{~g}, 16$ $\mathrm{mmol}$ ) was added dropwise. The reaction mixture was stirred at room temperature for $12 \mathrm{~h}$. After they were rinsed and dried under argon, the initiator grafted surfaces were used immediately for the polymerization reaction.

Poly(tert-butyl acrylate) (PtBA) was synthesized using surfaceinitiated atom transfer radical polymerization (SI-ATRP) following the procedure by Ikkala et al. ${ }^{61}$ The catalyst, copper(I) bromide $(\mathrm{CuBr})$, was synthesized through reduction of copper(II) sulfate pentahydrate by sodium sulfite. Monomethyl ether hydroquinone (inhibitor) was removed from tert-butyl acrylate by passing it through an alumina column. Initiator grafted surfaces from the previous step were placed into a solution of tert-butyl acrylate $(24.5 \mathrm{~g}, 190 \mathrm{mmol})$ in DMF $(14 \mathrm{~mL})$. Subsequently, $\mathrm{EBiB}(23.3 \mu \mathrm{L}, 0.16 \mathrm{mmol})$ and 
PMDETA (146.4 $\mu \mathrm{L}, 0.7 \mathrm{mmol})$ were dissolved, and the mixture was purged with argon for $15 \mathrm{~min}$. Afterward, $\mathrm{CuBr}(45.6 \mathrm{mg}, 0.32 \mathrm{mmol})$ and $\mathrm{CuBr}_{2}(7.2 \mathrm{mg}, 0.032 \mathrm{mmol})$ were added to the reaction mixture. Then, the reaction mixture was purged with argon for $15 \mathrm{~min}$ and finally placed in a preheated water bath at $75{ }^{\circ} \mathrm{C}$ to initiate the polymerization. The molar ratio of reactants was $[\mathrm{tBA}]:[\mathrm{EBiB}]$ : $[\mathrm{CuBr}]:\left[\mathrm{CuBr}_{2}\right]:[\mathrm{PMDETA}]=600: 0.5: 1: 0.1: 2.2$. The $\mathrm{P}(\mathrm{tBA})$ brushes were finally hydrolyzed in an acidic solution of trifluoroaceticacid $(9 \mathrm{~mL})$ in dichloromethane $(33 \mathrm{~mL})$ at room temperature for $24 \mathrm{~h}$.

Two samples with high grafting density $\left(0.62\right.$ chain $/ \mathrm{nm}^{2}$ and 0.58 chain $/ \mathrm{nm}^{2}$ ), low dispersity (1.12 and 1.10$)$, and different molecular weights were synthesized in this study (one with a relatively higher molecular weight suitable for ellipsometry-based studies of the effect of ionic strength and one with a relatively lower molecular weight suitable for QCM-D and ellipsometry-based studies of the effect of $\mathrm{pH})$. The molecular weights of the PtBAs synthesized in solution were $62100 \mathrm{~g} / \mathrm{mol}$ (so that the thickness-ionic strength test could be used to obtain a sensible variation in thickness) and $33700 \mathrm{~g} / \mathrm{mol}$ (for the $\mathrm{pH}$ titration tests). The molecular weight and dispersity were determined using GPC (see Supporting Information, section S2), and the grafting density was calculated according to the equation $\sigma=\frac{\rho h N_{\mathrm{A}}}{M_{\mathrm{n}}}$, assuming that the number-average molecular weight of the polymer chains synthesized in the solution phase is equal to that for chains tethered to the surface. ${ }^{11}$ The controlled nature of the polymerization was verified by the linearity of the conversion-time plot for the polymerization reaction (see Supporting Information, section S3).

Ellipsometry. Variable angle spectroscopic ellipsometry (M-2000, J. A. Woollam Co., Inc.) was employed to assess the thickness of the $\mathrm{P}(t \mathrm{BA})$ and PAA brush layers. The standard liquid cell of the instrument $(5 \mathrm{~mL}$ heated liquid cell) was used for the measurements in solution. The measurements were conducted over a wavelength range between 250 and $1000 \mathrm{~nm}$ and at an angle of incidence of $75^{\circ}$. For the titration test, the brush was kept in each $\mathrm{pH}$ for 40 min, which is longer than the estimated maximum time required for the PAA brush to reach equilibrium. ${ }^{36}$

In such experiments, p- and s-polarizied light waves are illuminated onto a sample. ${ }^{62,63}$ The light-matter interaction varies the polarization state of the reflected light, which is quantified in terms of ellipsometric $\psi(\lambda)$ (amplitude ratio) and $\Delta(\lambda)$ (phase shift). These two parameters are related to the sample properties through the complex reflectance function $(\rho)$ :

$$
\tan \psi \times \mathrm{e}^{i \Delta} \equiv \rho\left(\theta_{0}, h_{1}, \ldots, h_{j}, N_{a}, N_{s}, N_{1}, \ldots, N_{j}\right)
$$

Accordingly, the change in the polarization state of the reflected light depends on the angle of incidence $\left(\theta_{0}\right)$, the thickness of the layers $\left(h_{j}\right)$, as well as the complex refractive indices $\left(N_{j}=n_{j}+i k_{j}\right)$ of the layers, the ambient medium $\left(N_{\mathrm{a}}\right)$, and the substrate $\left(N_{\mathrm{s}}\right)$. Therefore, one has to construct an appropriate optical model describing the nominal structure of the sample with information on thickness and optical constants of all the components. Based on this model, the Fresnel coefficients of reflection for $\mathrm{p}$ - and s-waves can describe the changes in amplitude and phase at the interface. Next, the best match is found between the calculated and experimental $\psi(\lambda)$ and $\Delta(\lambda)$ through regression. The analysis of the data herein was conducted using the instrument software CompleteEASE (J.A. Woollam Co., Inc.).

The optical model herein comprises a thick Si substrate, an intermediate layer with a thickness of $1 \mathrm{~nm}, \mathrm{a} \mathrm{SiO}_{2}$ layer, and a transparent polymer layer. Before the brush layer was grafted, the thickness of the silicon oxide layer was determined in air. The optical dispersion of the polymer layer is described using the empirical Cauchy relation $\left(n=A+B / \lambda^{2}\right)$. For experiments in water and saline solutions with concentrations up to $100 \mathrm{mM}$, optical constants of pure water were used for the medium (Cauchy parameters of $A=1.322$ and $B=0.00327$ ). For saline solutions with higher concentrations, the difference in refractive index compared to water was calculated according to previous studies. ${ }^{64,65}$ Since both thickness and optical constants of the polymer film were unknown, the model comprises a total number of three free parameters (thickness, $A$, and $B$ of the polymer layer). Uniqueness of the estimated thickness values was checked using thickness-mean square error (MSE) plots. In addition, including roughness, thickness nonuniformity, grading, and anisotropy did not significantly improve the fitting quality (the modeling data are available in the Supporting Information, section S1).

Quartz Crystal Microbalance with Dissipation (QCM-D). Changes in the viscoelastic properties of the PAA brush in response to varying $\mathrm{pH}$ and ionic strength were studied using a Q-Sense E1 quartz crystal microbalance with dissipation (QCM-D) equipped with a standard Q-Sense flow module (Biolin Scientific, Gothenburg, Sweden).

For a QCM sensor surface (QSX335, Biolin Scientific, Gothenburg, Sweden) with an attached viscoelastic polymer layer (the PAA brush) immersed in saline solution, the measured changes in resonance frequency, $\Delta f$, and energy dissipation, $\Delta D$, can be modeled by the socalled Voigt model. ${ }^{66-68}$ Here, the polymer layer attached to the QCM sensor surface is represented as a film of uniform thickness and density coupled to a Newtonian fluid under nonslip conditions and is characterized by a given elastic shear modulus and shear viscosity. The relationship between the measured values of $\Delta f$ and $\Delta D$, respectively, and the physical properties of the system is given by

$$
\begin{gathered}
\Delta f=\frac{\operatorname{Im}(\beta)}{2 \pi t_{q} \rho_{q}} \\
\Delta D=\frac{\operatorname{Re}(\beta)}{\pi f t_{q} \rho_{q}}
\end{gathered}
$$

where

$$
\beta=\frac{\xi_{1} \omega \eta_{1}-i \mu_{1}}{\omega} \frac{1-\alpha^{2} \xi_{1} h_{1}}{1+\alpha^{2} \xi_{1} h_{1}}
$$

and

$$
\begin{aligned}
& \alpha=\frac{\frac{\xi_{1} \omega \eta_{1}-i \mu_{1}}{\xi_{2} \omega \eta_{2}}+1}{\frac{\xi_{1} \omega \eta_{1}-i \mu_{1}}{\xi_{2} \omega \eta_{2}}-1} \\
& \xi_{1}=\sqrt{-\frac{\omega^{2} \rho_{1}}{\mu_{1}+i \omega \eta_{1}}} \\
& \xi_{2}=\sqrt{i \frac{\omega \rho_{2}}{\eta_{2}}}
\end{aligned}
$$

By plotting eqs 2 and 3 as a function of the polymer layer thickness, one will observe that for given values of $\rho_{\mathrm{s}}, \rho_{\mathrm{p}}, \eta_{\mathrm{s}}, \eta_{\mathrm{p}}$, and $\mu_{\mathrm{p}}, \Delta f$ and $\Delta D$ are highly sensitive to changes in film thickness up to a certain thickness. However, there exists a range of layer thicknesses beyond which $\Delta f$ and $\Delta D$ become relatively insensitive to further increases in layer thickness. ${ }^{60}$ The film thicknesses where $\Delta f$ and $\Delta D$ are either sensitive or insensitive to changes in the film thickness have in previous work been referred to as the limited cases of thin and thick films, respectively. ${ }^{69}$ Physically, the change in sensitivity of $\Delta f$ and $\Delta D$ are related to the situations where the polymer layer is either much thinner or much thicker than the characteristic decay length, $\delta$, of the shear wave traveling in the normal direction from the QCM sensor surface through the polymer layer and the overlaying fluid. ${ }^{70}$ The decay length is defined as

$$
\delta=\sqrt{\frac{2 \eta_{x}}{\rho_{x} \omega}}
$$

where $\eta_{x}$ and $\rho_{x}$ here refer to the shear viscosity and density of either the fluid or the polymer layer depending on whether one is solving for the limited case of a thin or a thick film, respectively. 
For a PAA brush layer in aqueous solution the decay length can be estimated to approximately $250 \mathrm{~nm}$ for the fundamental frequency of the propagating wave and approximately $70 \mathrm{~nm}$ for the 13th overtone of the propagating wave. For these calculations the density was set to $1043 \mathrm{~kg} / \mathrm{m}^{3}$ [corresponding to the density of our PAA brush layer with a $70 \%$ water content (derived from our ellipsometry data of the PAA brush at intermediate $\mathrm{pH}$ by use of the BEMA model) and by assuming ideal mixing of water and PAA]. The viscosity was set to 1 $\mathrm{mPa} \cdot \mathrm{s}$ corresponding to the shear viscosity previously reported for a $38 \mathrm{~nm}$ PAA brush. ${ }^{.0}$ Thus, for brush layers with thicknesses of the order of $100 \mathrm{~nm}$, neither the conditions for the limited cases of thin nor thick films are fulfilled; therefore, the different overtones will respond differently to changes in the film thickness. ${ }^{60}$ As will be demonstrated further in the results section, in this work, we have taken advantage of this fact to probe different depths of the polymer layer by using the different measured overtones of frequency and dissipation. It should, however, be stressed that the decay lengths are numbers reflecting the decay rate of the acoustic waves of the different overtone harmonics and not numbers related to exact vertical positions in the brush. The various overtone harmonics thus sense the layer with a different weighted average where the higher overtone harmonic mainly senses the inner part of the brush layer and the lower overtone harmonic sense both the inner and more outer part of the brush layer.

\section{RESULTS AND DISCUSSION}

As described in the experimental sections, we have synthesized PAA brush layers with a fixed grafting density, and in the following, we will discuss how such brush layers respond to changes in $\mathrm{pH}$ and ionic strength. However, before presenting our experimental results, we briefly recapitulate the theoretically expected behavior of polyelectrolyte brushes, particularly the behavior of weak polyelectrolyte brushes. For further theoretical considerations, the reader is referred to the original works and some newer summaries. ${ }^{3,5,6,8-11,30,57}$

For a strong polyelectrolyte brush at moderate-to-high grafting density and at low salt concentration, $\phi_{s}$, the counterions will be restricted to the volume of the brush layer, which leads to a swollen brush, where the osmotic pressure of the counterions is balanced by chain contraction and where the brush height, $H$, scales as

$$
H \propto N f^{1 / 2}
$$

Here, $N$ is the number of chain segments and $f$ is the fraction of monomers carrying a permanent charge. In this regime, the brush height is thus independent of the grafting density, $\sigma$, and the salt concentration, $\phi_{s}$. However, when $\phi_{s}$ exceeds a certain value, the brush enters the salted brush regime where the added salt significantly starts to screen the electrostatic interactions in the brush layers and the osmotic pressure is reduced. In this salted brush regime, the brush height scales as

$$
H \propto N \sigma^{1 / 3}\left(\frac{f^{2}}{\varphi_{s}}\right)^{1 / 3}
$$

Thus, in the salted brush regime, the layer will shrink by increasing $\phi_{s}$ until the influence of electrostatic interactions diminishes and the excluded volume effects determine the brush structure. By equating the scaling laws for the osmotic and the salted brush regimes, the crossover between these regimes is found to be

$$
\varphi_{s} \propto \sigma f^{1 / 2}
$$

The behavior of a weak polyelectrolyte brush is unlike that of a strong polyelectrolyte brush because the charge fraction is not constant but depends on the degree of dissociation of acid or basic groups. In our case of a polyacid, the degree of dissociation, $\alpha$, is given by the acid-base equilibrium

$$
\mathrm{HA} \leftrightarrows \mathrm{A}^{-}+\mathrm{H}^{+}
$$

and $\alpha$ then becomes

$$
\alpha=\frac{K_{\mathrm{D}}}{K_{\mathrm{D}}+\left[\mathrm{H}^{+}\right]}
$$

Here, $K_{\mathrm{D}}$ is the dissociation constant for the acid-base equilibrium and $\left[\mathrm{H}^{+}\right]=10^{-\mathrm{pH}}$ is the proton concentration. For a polyacid brush layer, this simple relation directly implies that the degree of dissociation in the brush is not only a function of the polymer chemistry but also a function of the local $\mathrm{pH}$ value, which again is controlled by the bulk $\mathrm{pH}$, ionic strength, and local polymer density.

In the salted brush regimes, where there exists an excess of salt in the bulk, the concentration of protons in the brush becomes approximately equal to the concentration of protons in the bulk; the internal degree of dissociation is thus approximately the same as it would be for a diluted chain. Hence, in the salted brush regime of a weak polyelectrolyte, the brush height follows a similar scaling relation as for a strong polyelectrolyte:

$$
H \propto N \sigma^{1 / 3}\left(\frac{\alpha^{2}}{\varphi_{s}}\right)^{1 / 3}
$$

where the brush height, however, scales with the dissociation degree of an isolated chain in the bulk, $\alpha$, instead of with the fixed charge fraction, $f$.

On the other hand, in the osmotic brush regime, the activity of the counterions is too low to substitute all the protons in the brush originating from dissociation of the acid groups; the concentration of protons in the brush will thus be higher than in the bulk. In response to this unfavorable condition, the brush will undergo a charge regulation process, which leads to a dissociation degree, $\alpha_{0}$, that is lower than expected from the bulk $\mathrm{pH}$ value $\left(\alpha_{0}<\alpha\right)$. Consequently, $\alpha_{0}$ will increase with increasing ionic strength, and, in this regime, the brush height of a weak polyelectrolyte (polyacid) will scale as

$$
H \propto N \sigma^{-1 / 3}\left(\frac{\alpha}{1-\alpha}\right)^{1 / 3}\left(\left[\mathrm{H}^{+}\right]+\varphi_{s}\right)^{1 / 3}
$$

where $\alpha$ again is the dissociation degree of a diluted chain in the bulk, $\left[\mathrm{H}^{+}\right]$is the proton concentration in the bulk, and $\phi_{s}$ is the concentration of added salt, while the local polymer concentration in this approach is indirectly given by the grafting density, $\sigma$.

In the following, we have experimentally evaluated how the PAA brush height is affected by the bulk $\mathrm{pH}$ and the ionic strength in accordance with eq 15 , as well as how the local degree of dissociation supposedly varies with the vertical position in the brush. To compare experiments conducted on different prepared brush layers, we present the brush heights normalized by the PAA chain contour lengths (see Supporting Information, section S5). This can be done because the brush height, according to eqs 14 and 15 , scales linearly with the number of monomers, $N$, in both the salted brush and osmotic brush regimes. 
Effect of Ionic Strength at Fixed pH. As a first step, we employed in situ spectroscopic ellipsometry to measure the height of the PAA brush as a function of ionic strength at fixed bulk $\mathrm{pH}$ values of 6 and 9, respectively. After each change in environmental condition (ionic strength or $\mathrm{pH}$ ) the in situ ellipsometry signals were followed, and the equilibrium thickness was defined as the thickness measured over a time interval of $10 \mathrm{~min}$ where the variation in thickness was less than $0.1 \mathrm{~nm}$. As seen in Figure 1, the brush height at both $\mathrm{pH}$

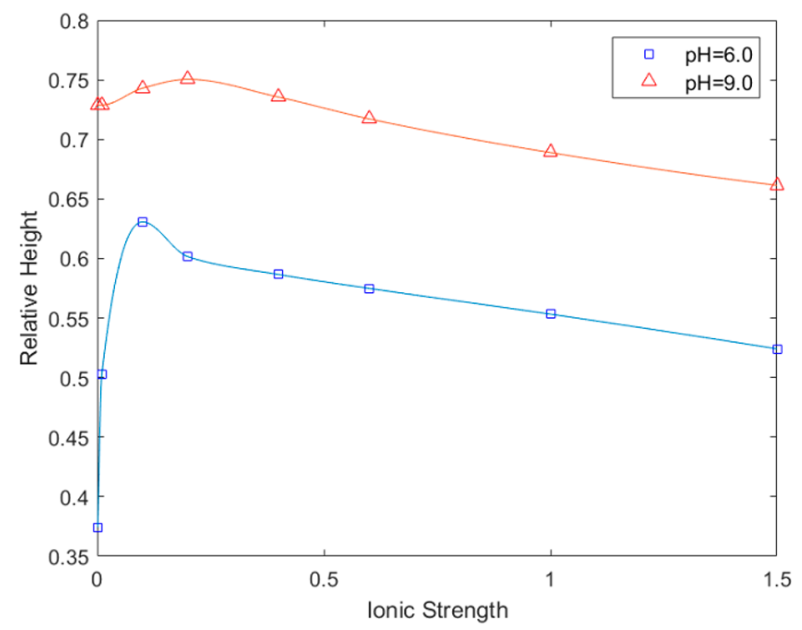

Figure 1. Ellipsometry-based normalized PAA brush height measure as a function of ionic strength at $\mathrm{pH} 6$ (blue) and $\mathrm{pH} 9$ (red). Lines are guides to the eye.

values is a nonmonotonic function of the ionic strength. At low ionic strength, where the brush is found in the osmotic brush regime, the brush height increases with increasing ionic strength because of the increasing degree of dissociation. Oppositely, at high ionic strength, where the brush is found in the salted brush regime, the brush height decreases with increasing ionic strength because of increased electrostatic screening. By comparing the results obtained at the two different $\mathrm{pH}$ values, three interesting observations can be made. First, it is observed that the brush layer at all ionic strengths is significantly more stretched at $\mathrm{pH} 9$ compared to at $\mathrm{pH}$ 6. This indicates a higher dissociation degree and, thus, a larger osmotic pressure at the higher $\mathrm{pH}$ value. This behavior is to be expected for a polyacid. Second, it is observed that the relative change in brush height is much smaller at $\mathrm{pH} 9$ than at $\mathrm{pH}$ 6. This behavior occurs along the same lines, because the charge regulation process in the osmotic brush regime is much smaller at a $\mathrm{pH}$ value far above the $\mathrm{p} K_{\mathrm{a}}$ value compared to that at a $\mathrm{pH}$ value close to the $\mathrm{p} K_{\mathrm{a}}$ value. Third, it is observed that the ionic strength, which gives rise to the maximum brush height at each respective $\mathrm{pH}$ value is higher at $\mathrm{pH} 9$ compared to at $\mathrm{pH}$ 6. This observation is in agreement with the scaling prediction (eq 11). The fact that the crossover between the osmotic brush regime and the salted brush regime is found at approximately $100-200 \mathrm{mM} \mathrm{NaCl}$ also means that for studies of the effect of varying ionic strength on the degree of dissociation, one should operate at salt concentrations below this level.

Effect of $\mathrm{pH}$ at Fixed Ionic Strength. Next, we investigated the effect of bulk $\mathrm{pH}$ value on the relative PAA brush height at three fixed ionic strengths, which are chosen such that the brush is expected to be found in the osmotic brush regime in all three cases. Figure 2 presents the relative PAA brush height as a function of $\mathrm{pH}$ in aqueous solutions of 1

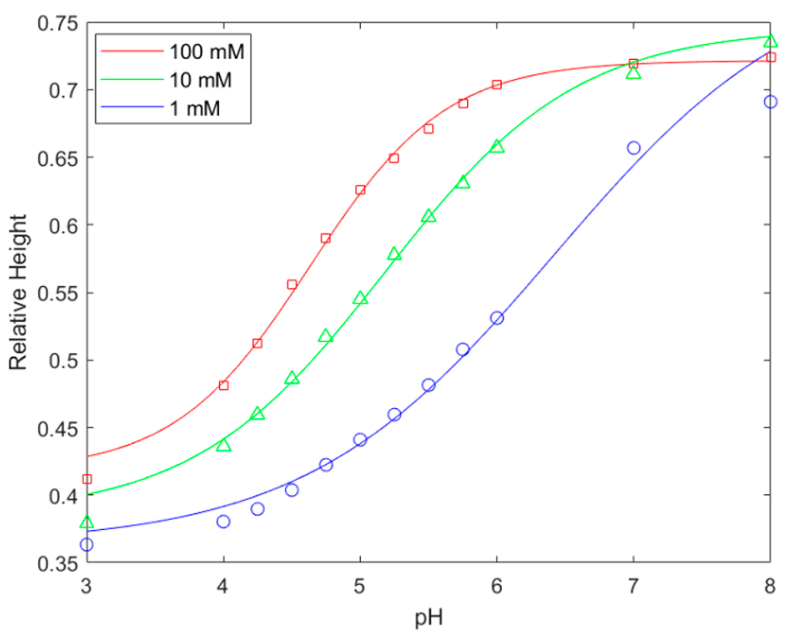

Figure 2. Ellipsometry-based normalized PAA brush height as a function of $\mathrm{pH}$ at $1 \mathrm{mM}$ (blue), $10 \mathrm{mM}$ (green), and $100 \mathrm{mM}$ (red) $\mathrm{NaCl}$.

$\mathrm{mM}, 10 \mathrm{mM}$, and $100 \mathrm{mM} \mathrm{NaCl}$ measured with spectroscopic ellipsometry. At all three ionic strengths, similar trends are observed, and the trends, which are due to the charging of the brush, are in agreement with previous studies on PAA brush layers ${ }^{18,19,37,38,42}$ and other weak polyelectrolyte brushes. ${ }^{13,18,39-41,43}$ At low $\mathrm{pH}$, where the brush can be assumed to be almost uncharged, the brush height is reduced to approximately $40 \%$ of its maximum value and is only weakly dependent on $\mathrm{pH}$. Oppositely, at high $\mathrm{pH}$, where the brush can be assumed to be highly charged, the brush height is increased to approximately $75 \%$ of its maximum value and is again only weakly dependent on $\mathrm{pH}$. At intermediate $\mathrm{pH}$ values, one finds the transition zone, where the PAA chains undergo a charge regulation process which, according to the above-presented theory, should depend on the bulk $\mathrm{pH}$, ionic strength, and the local polymer concentration. As a first observation, one notes that the relative brush height starts to increase at lower $\mathrm{pH}$ for higher ionic strength compared to for lower ionic strength. This is in agreement with the scaling relation for a weak polyacid in the osmotic brush regime (eq 15). Next, as the increase in the relative brush height results from the increased number of dissociated acid groups and the subsequent increased osmotic pressure in the brush, we assume that the apparent $\mathrm{p} K_{\mathrm{a}}$ value of the brush layer to a first approximation can be determined from the midpoint of a sigmoid function fitted to the relative brush height versus bulk $\mathrm{pH}$ values (see Supporting Information, section S4). By using this approach, we determined the apparent $\mathrm{p} K_{\mathrm{a}}$ values to be 6.4, 5.2, and 4.6 at 1,10 , and $100 \mathrm{mM} \mathrm{NaCl}$, respectively. It should again be stressed that we use the term apparent $\mathrm{p} K_{\mathrm{a}}$ because the value is taken relative to the bulk $\mathrm{pH}$ value and not the local $\mathrm{pH}$ value in the brush and because it is related to the inflection point of the swelling transition, which does not necessarily correspond to the situation where $50 \%$ of the acid groups are dissociated.

Local Dissociation Degree through the Brush. In addition to the dependence on the bulk $\mathrm{pH}$ and ionic strength, the degree of dissociation and, therefore, the apparent $\mathrm{p} K_{\mathrm{a}}$ value also depend on the proximity to other dissociable groups, i.e., the local polymer density. As discussed in relation to eq 15, 
the local PAA density can thus be tuned by the grafting density, and it is known that an increased grafting density can lead to a decreased degree of dissociation at a constant ionic strength and bulk $\mathrm{pH}$ value. ${ }^{46}$ In our case where the grafting density is constant, one can, however, expect a variation in the local PAA density as a function of the vertical position in the brush due to the expected approximately parabolic density profile. However, although such a variation in the degree of dissociation is expected from basic considerations and has been demonstrated in theoretical studies, it has never been experimentally verified. ${ }^{6,56,57}$

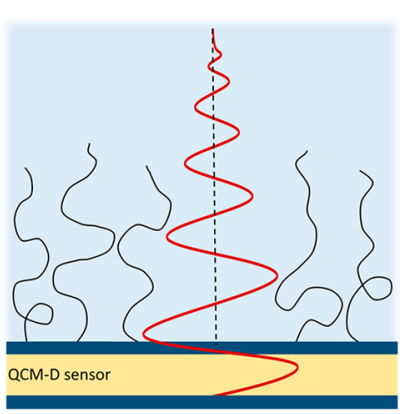

Fundamental mode

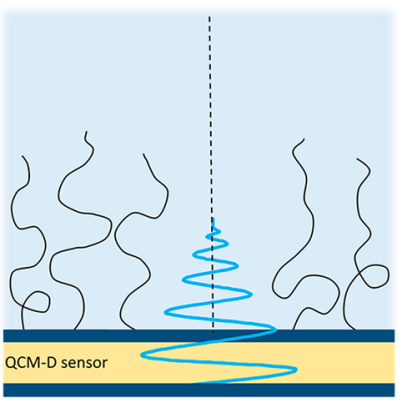

Intermediate harmonic

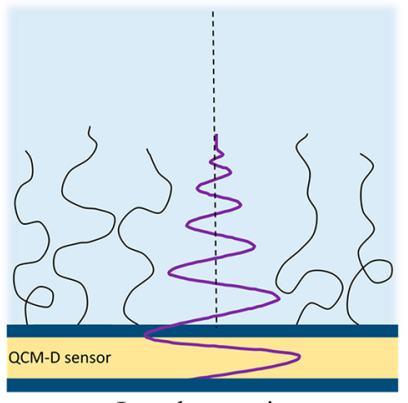

Low harmonic

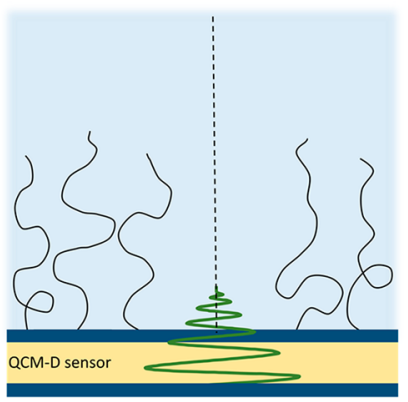

High harmonic
Figure 3. Schematic illustration of the acoustic wave decay for various oscillatory modes.

To probe the local variation in the dissociation degree through the brush layer vertically, we employed QCM-D. As discussed in the details in the Experimental Section, we here take advantage of the fact that the PAA brush layer thickness is comparable to the magnitude of the decay length of the shear wave propagating in the normal direction to the QCM sensor surface. In such a case, the measured frequencies and dissipation values associated with different overtones of the oscillation of the QCM sensor with the attached PAA brush probe different parts of the brush layer with different weights, as illustrated in Figure 3. Thus, for any overtone number, the sensitivity will decrease with the distance from the sensor surface. However, due to the different decay lengths of the different overtones, the lower overtone numbers will probe a relatively larger fraction of the outer part of the brush layer, compared to the higher overtone numbers.

Figure 4 shows the overtone dependence of the frequency and dissipation as a function of bulk $\mathrm{pH}$ at 1,10 , and $100 \mathrm{mM}$ $\mathrm{NaCl}$. The dissipation value is dependent on the conformational changes in the brush layer and will, in general, increase with increasing brush height. Thus, the overall appearance of the dissipation as a function of bulk $\mathrm{pH}$ for any overtone and at any ionic strength has a similar shape as the brush height as a function of $\mathrm{pH}$ obtained by ellipsometry-with a low and approximately constant value at low $\mathrm{pH}$, a high and approximately constant value at high $\mathrm{pH}$, and a rapid changing value at intermediate $\mathrm{pH}$ values. The change in frequency is mainly related to the change in the sensed mass, which increases when the brush layer swells, as seen in Figure 4. Thus, the overall appearance of the frequency as a function of bulk $\mathrm{pH}$ follows an opposite trend compared to the change in dissipation. The growth in dissipation and decline in frequency with increasing $\mathrm{pH}$ is in agreement with previous QCM-D data reported in the literature for PAA brush layers. ${ }^{71-75}$ This is due to formation of charges, which makes the weak polyelectrolyte brush highly hydrated. Similar trends have been observed for other weak polyelectrolyte brushes as well. ${ }^{40,43,46-48,76}$

To compare the apparent $\mathrm{p} K_{\mathrm{a}}$ values at different decay lengths with the apparent $\mathrm{p} K_{\mathrm{a}}$ values found from the ellipsometry data, we fitted the same sigmoid function to the dissipation versus bulk $\mathrm{pH}$ data at three different ionic strengths. A similar analysis based on the frequency data is presented in the Supporting Information, section S6. However, as discussed in section S6, the dissipation values are mostly related to the structural changes in the brush layer, and the apparent $\mathrm{p} K_{\mathrm{a}}$ values obtained from the dissipation values are thus more comparable to the apparent $\mathrm{p} K_{\mathrm{a}}$ values obtained from the ellipsometry data. The results of this exercise are shown in Figure 5(a), and three main observations can be made. As a first observation, the apparent $\mathrm{p} K_{\mathrm{a}}$ decreases with increasing decay length at all three ionic strengths. As the brush layer is expected to show a higher density deep into the brush and a decaying density closer to the outer part of the brush (approximately parabolic profile), ${ }^{4,52-54}$ this observation is in agreement with that expected and with results from previous theoretical calculations. ${ }^{6,56,57}$ As a second observation, the apparent $\mathrm{p} K_{\mathrm{a}}$ value at any decay length decreases with increasing ionic strength. This observation is in agreement with the scaling prediction (eq 15), where the results are based on the ellipsometry measurements and previous experimental results. ${ }^{38}$ As a third observation, the variation in the apparent $\mathrm{p} K_{\mathrm{a}}$ as one moves vertically through the brush is much more significant at low ionic strength compared to that at high ionic strength. The reason for this is that the electrostatic interaction leading to increased discharging at higher local PAA densities is more effectively screened at higher ionic strength when the charge regulation is less significant. This point is further illustrated in Figure 5(b), where the dissociation degree at $\mathrm{pH}$ 5.0 (which corresponds to the average $\mathrm{p} K_{\mathrm{a}}$ value across all decay lengths and ionic strengths) is plotted against the decay length. The dissociation degrees were here calculated by using the equilibrium constants derived from the apparent $\mathrm{p} K_{\mathrm{a}}$ values presented in Figure 5(a) and the $[\mathrm{H}+]$ concentration in bulk. From Figure 5(b), it is seen that the charge fraction varies from 0.02 to approximately 0.49 at $1 \mathrm{mM} \mathrm{NaCl}$, while it varies from approximately 0.65 to approximately 0.87 at $100 \mathrm{mM} \mathrm{NaCl}$. Notably, this means that at this intermediate $\mathrm{pH}$ value, the acid groups can be either almost completely protonated or almost fully deprotonated depending on the ionic strength and vertical position in the brush layer. For future studies we suggest that the vertical counterion distribution should be investigated as a function of $\mathrm{pH}$. Previously, contrast variant neutron reflectivity and small-angle X-ray scattering have been employed to study counterion distributions in layers of weak and strong polyelectrolyte. ${ }^{77-79}$ Thus, by assuming some degree of local charge neutrality, one could speculate that the counterion 

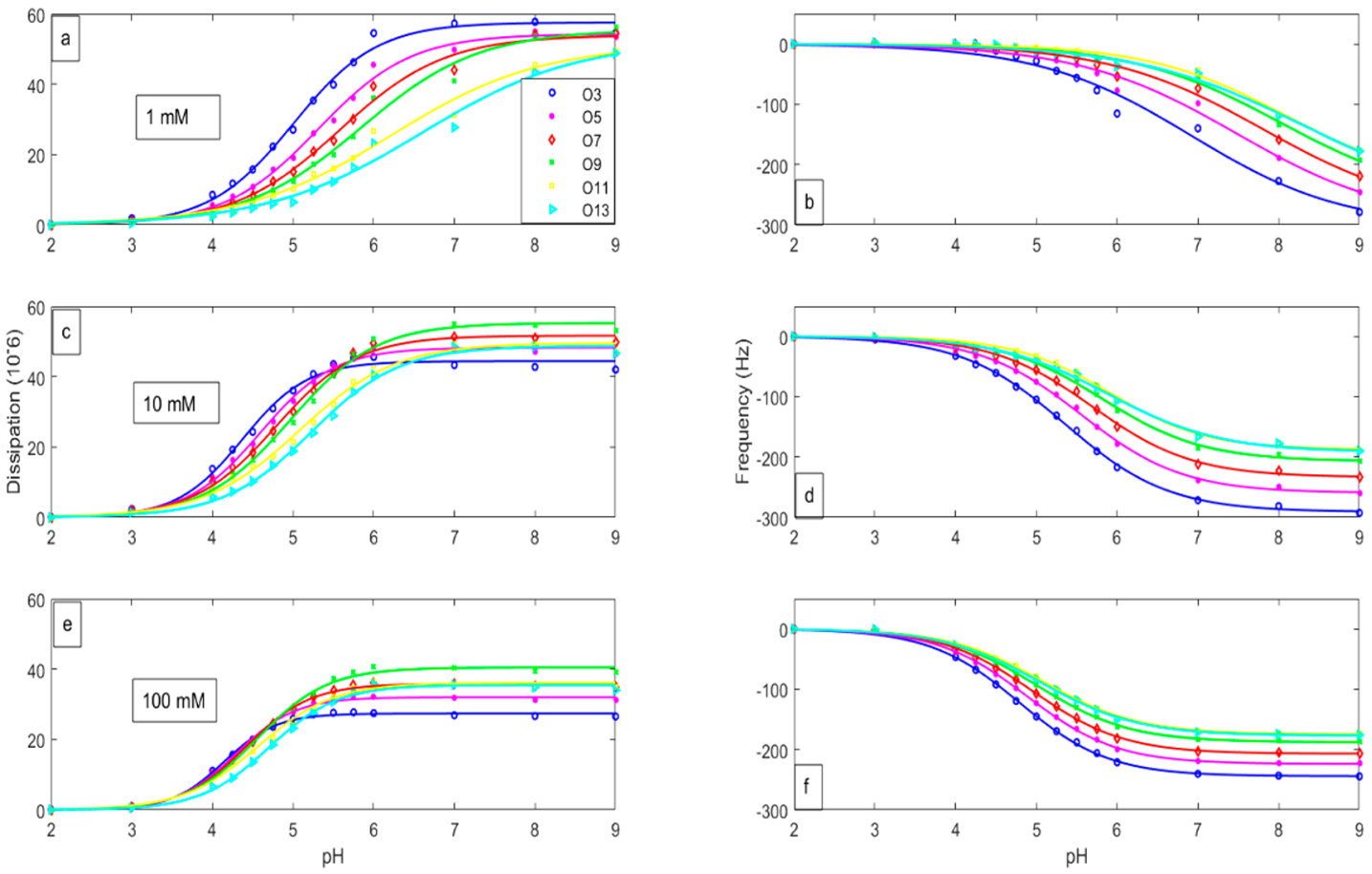

Figure 4. QCM-D-based dissipation shift at $1 \mathrm{mM}$ (a), $10 \mathrm{mM}$ (c), and $100 \mathrm{mM} \mathrm{NaCl}(\mathrm{e})$ and frequency shift at $1 \mathrm{mM}(\mathrm{b}), 10 \mathrm{mM}(\mathrm{d})$, and 100 $\mathrm{mM} \mathrm{NaCl}$ (f) for the PAA brush as a function of $\mathrm{pH}$ at different overtone harmonics (O3-O13). The lines show results of the fitting according to the sigmoid function.
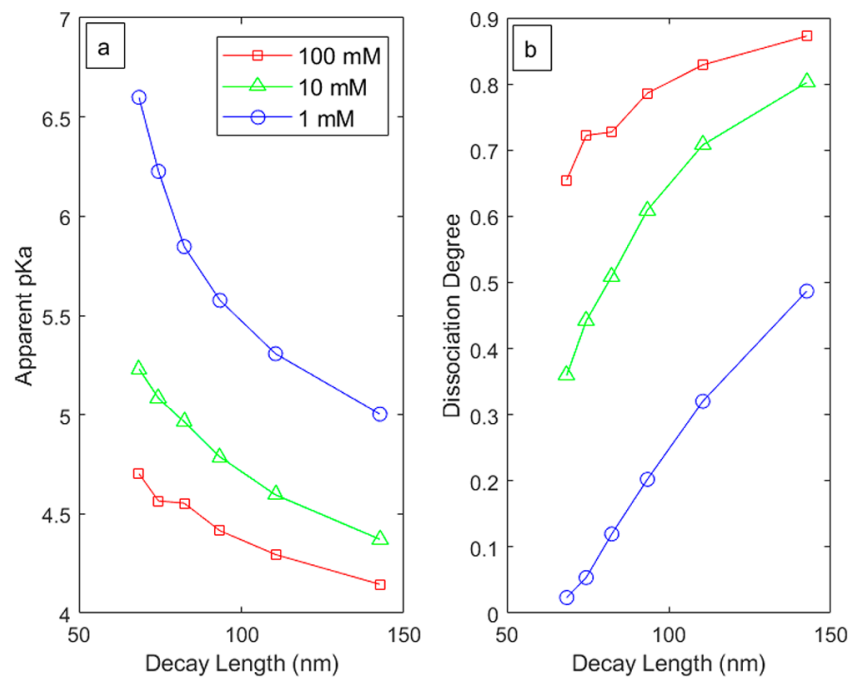

Figure 5. Apparent $\mathrm{p} K_{\mathrm{a}}$ value (a) and dissociation degree at $\mathrm{pH}=5.0$ (b) as a function of the decay length, as determined by the QCM-Dbased dissipation data presented in Figure 4.

distribution should be correlated to the vertical dissociation profile in the brush.

\section{CONCLUSION}

In this work, we investigated the structural and mechanical variations in a PAA brush as a function of $\mathrm{pH}$ and ionic strength. The overarching goal of this investigation was to provide experimental evidence for variation in the dissociation behavior of a brush layer in the vertical direction. To do so, we first had to identify the osmotic brush regime by measuring the brush thickness as a function of ionic strength at different $\mathrm{pH}$ values. Thereafter, the properties of the osmotic brush were investigated as a function of $\mathrm{pH}$ at three different ionic strengths. By taking advantage of the variation in penetration depth of various overtone harmonics in QCM-D, we showed that the degree of dissociation increases with increasing distance from the substrate for a given value of $\mathrm{pH}$ and ionic strength. Moreover, increasing the ionic strength increases the average degree of dissociation and lowers the variation in the degree of dissociation in the brush in the vertical direction. As an example of the significant effects of these parameters, we showed that at an intermediate $\mathrm{pH}$ (approximately $\mathrm{pH} 5$ ), the response from the acidic groups indicates that they can be almost uncharged or almost fully charged depending on the ionic strength and vertical position in the brush.

\section{ASSOCIATED CONTENT}

\section{SI Supporting Information}

The Supporting Information is available free of charge at https://pubs.acs.org/doi/10.1021/acs.langmuir.9b03537.

(S1) Analysis of the ellipsometry data; (S2) determination of the sample molecular weight; (S3) conversiontime plot for the controlled radical polymerization; (S4) fitting data points to the sigmoid function to find the $\mathrm{pKa}$ value; (S5) relative height calculation; (S6) obtaining apparent $\mathrm{pKa}$ values from frequency data (PDF)

\section{AUTHOR INFORMATION}

\section{Corresponding Author}

Esben Thormann - Department of Chemistry, Technical University of Denmark, 2800 Kgs. Lyngby, Denmark; 다이.org/0000-0002-2364-3493; Email: esth@ kemi.dtu.dk 


\section{Authors}

Koosha Ehtiati - Department of Chemistry, Technical University of Denmark, 2800 Kgs. Lyngby, Denmark

Saeed Z. Moghaddam - Department of Chemistry, Technical University of Denmark, 2800 Kgs. Lyngby, Denmark; (i) orcid.org/0000-0002-6536-7490

Anders E. Daugaard - Danish Polymer Center, Department of Chemical and Biochemical Engineering, Technical University of Denmark, 2800 Kgs. Lyngby, Denmark; 으orcid.org/00000002-0627-6310

Complete contact information is available at:

https://pubs.acs.org/10.1021/acs.langmuir.9b03537

\section{Notes}

The authors declare no competing financial interest.

\section{ACKNOWLEDGMENTS}

K.E. and E.T. greatly acknowledge the financial support from the Independent Research Fund Denmark (6108-00128B).

\section{REFERENCES}

(1) Alexander, S. Adsorption of Chain Molecules with a Polar Head a Scaling Description. J. Phys. (Paris) 1977, 38, 983-987.

(2) de Gennes, P. G. Conformations of Polymers Attached to an Interface. Macromolecules 1980, 13, 1069-1075.

(3) Israëls, R.; Leermakers, F. A. M.; Fleer, G. J. On the Theory of Grafted Weak Polyacids. Macromolecules 1994, 27, 3087-3093.

(4) Seidel, C. Strongly stretched polyelectrolyte brushes. Macromolecules 2003, 36, 2536-2543.

(5) Israëls, R.; Leermakers, F. A. M.; Fleer, G. J.; Zhulina, E. B. Charged Polymeric Brushes: Structure and Scaling Relations. Macromolecules 1994, 27, 3249-3261.

(6) Zhulina, E. B.; Borisov, O. V. Poisson-boltzmann theory of pHsensitive (annealing) polyelectrolyte brush. Langmuir 2011, 27, 10615-10633.

(7) Borisov, O. V.; Zhulina, E. B.; Birshtein, T. M. Diagram of the States of a Grafted Polyelectrolyte Layer. Macromolecules 1994, 27, 4795-4803.

(8) Lyatskaya, Yu. V.; Leermakers, F. A. M.; Fleer, G. J.; Zhulina, E. B.; Birshtein, T. M. Analytical Self-Consistent-Field Model of Weak Polyacid Brushes. Macromolecules 1995, 28, 3562-3569.

(9) Zhulina, E. B.; Birshtein, T. M.; Borisov, O. V. Theory of Ionizable Polymer Brushes. Macromolecules 1995, 28, 1491-1499.

(10) Pincus, P. Colloid Stabilization with Grafted Polyelectrolytes. Macromolecules 1991, 24, 2912-2919.

(11) Wu, T.; Gong, P.; Szleifer, I.; Vlcek, P.; Subr, V.; Genzer, J. Behavior of surface-anchored poly (acrylic acid) brushes with grafting density gradients on solid substrates: 1 . Experiment. Macromolecules 2007, 40, 8756-8764.

(12) Zhang, H.; Rühe, J. Swelling of poly(methacrylic acid) brushes: Influence of monovalent salts in the environment. Macromolecules 2005, 38, 4855-4860.

(13) Biesalski, M.; Rühe, J. Scaling laws for the swelling of neutral and charged polymer brushes in good solvents. Macromolecules 2002, 35, 499-507.

(14) Moh, L. C. H.; Losego, M. D.; Braun, P. V. Solvent quality effects on scaling behavior of poly(methyl methacrylate) brushes in the moderate- and high-density regimes. Langmuir 2011, 27, 36983702.

(15) Dunlop, I. E.; Thomas, R. K.; Titmus, S.; Osborne, V.; Edmondson, S.; Huck, W. T. S.; Klein, J. Structure and collapse of a surface-grown strong polyelectrolyte brush on sapphire. Langmuir 2012, 28, 3187-3193.

(16) Hadziioannou, G.; Patel, S.; Granick, S.; Tirrell, M. Forces between Surfaces of Block Copolymers Adsorbed on Mica. J. Am. Chem. Soc. 1986, 108, 2869-2876.
(17) Patel, S.; Tirrell, M.; Hadziioannou, G. Forces Between Layers of Adsorbed Block Copolymers. Am. Chem. Soc. Polym. Prepr. Div. Polym. Chem. 1987, 28, 42-43.

(18) Biesalski, M.; Johannsmann, D.; Rühe, J. Synthesis and swelling behavior of a weak polyacid brush. J. Chem. Phys. 2002, 117, 49884994.

(19) Lego, B.; Skene, W. G.; Giasson, S. Swelling study of responsive polyelectrolyte brushes grafted from mica substrates: Effect of $\mathrm{pH}$, salt, and grafting density. Macromolecules 2010, 43, 4384-4393.

(20) Chen, M.; Briscoe, W. H.; Armes, S. P.; Klein, J. Lubrication at physiological pressures by polyzwitterionic brushes. Science 2009, 323, $1698-1701$.

(21) Wei, Q.; Cai, M.; Zhou, F.; Liu, W. Dramatically Tuning Friction Using Responsive Polyelectrolyte Brushes. Macromolecules 2013, 46, 9368-9379.

(22) Kobayashi, M.; Terayama, Y.; Hosaka, N.; Kaido, M.; Suzuki, M.; Yamada, N.; Torikai, N.; Ishihara, K.; Takahara, A. Friction behavior of high-density poly (2-methacryloyloxyethyl phosphorylcholine) brush in aqueous media. Soft Matter 2007, 3, 740-746.

(23) Liu, X.; Dedinaite, A.; Rutland, M.; Thormann, E.; Visnevskij, C.; Makuska, R.; Claesson, P. M. Electrostatically anchored branched brush layers. Langmuir 2012, 28, 15537-15547.

(24) Liu, X.; Thormann, E.; Dedinaite, A.; Rutland, M.; Visnevskij, C.; Makuska, R.; Claesson, P. M. Low friction and high load bearing capacity layers formed by cationic-block-non-ionic bottle-brush. Soft Matter 2013, 9, 5361-5371.

(25) Kobayashi, M.; Terayama, Y.; Yamaguchi, H.; Terada, M.; Murakami, D.; Ishihara, K.; Takahara, A. Wettability and antifouling behavior on the surfaces of superhydrophilic polymer brushes. Langmuir 2012, 28, 7212-7222.

(26) Kuang, J.; Messersmith, P. B. Universal surface-initiated polymerization of antifouling zwitterionic brushes using a musselmimetic peptide initiator. Langmuir 2012, 28, 7258-7266.

(27) Yang, W. J.; Neoh, K. G.; Kang, E. T.; Teo, S. L. M.; Rittschof, D. Polymer brush coatings for combating marine biofouling. Prog. Polym. Sci. 2014, 39, 1017-1042.

(28) Stuart, M. A. C.; Huck, W. T. S.; Genzer, J.; Ober, C.; Stamm, M.; Sukhorukov, G. B.; Szleifer, I.; Tsukruk, V. V.; Urban, M.; Winnik, F.; Zauscher, S.; Luzinov, I.; Minko, S.; Müller, M. Emerging applications of stimuli-responsive polymer materials. Nat. Mater. 2010, 9, 101-113.

(29) Chen, T.; Ferris, R.; Zhang, J.; Ducker, R.; Zauscher, S. Stimulus-responsive polymer brushes on surfaces: Transduction mechanisms and applications. Prog. Polym. Sci. 2010, 35, 94-112.

(30) Willott, J. D.; Murdoch, T. J.; Webber, G. B.; Wanless, E. J. Physicochemical behaviour of cationic polyelectrolyte brushes. Prog. Polym. Sci. 2017, 64, 52-75.

(31) Welch, M. E.; Ober, C. K. Responsive and patterned polymer brushes. J. Polym. Sci., Part B: Polym. Phys. 2013, 51, 1457-1472.

(32) Chen, W. L.; Cordero, R.; Tran, H.; Ober, C. K. 50th Anniversary Perspective: Polymer Brushes: Novel Surfaces for Future Materials. Macromolecules 2017, 50, 4089-4113.

(33) Zoppe, J. O.; Ataman, N. C.; Mocny, P.; Wang, J.; Moraes, J.; Klok, H. A. Surface-Initiated Controlled Radical Polymerization: State-of-the-Art, Opportunities, and Challenges in Surface and Interface Engineering with Polymer Brushes. Chem. Rev. 2017, 117, $1105-1318$

(34) Azzaroni, O. Polymer brushes here, there, and everywhere: Recent advances in their practical applications and emerging opportunities in multiple research fields. J. Polym. Sci., Part A: Polym. Chem. 2012, 50, 3225-3258.

(35) Dong, R.; Lindau, M.; Ober, C. K. Dissociation behavior of weak polyelectrolyte brushes on a planar surface. Langmuir 2009, 25, 4774-4779.

(36) Yadav, V.; Harkin, A. V.; Robertson, M. L.; Conrad, J. C. Hysteretic memory in $\mathrm{pH}$-response of water contact angle on poly(acrylic acid) brushes. Soft Matter 2016, 12, 3589-3599.

(37) Aulich, D.; Hoy, O.; Luzinov, I.; Brucher, M.; Hergenroder, R.; Bittrich, E.; Eichhorn, K. J.; Uhlmann, P.; Stamm, M.; Esser, N.; 
Hinrichs, K. In situ studies on the switching behavior of ultrathin poly(acrylic acid) polyelectrolyte brushes in different aqueous environments. Langmuir 2010, 26, 12926-12932.

(38) Currie, E. P. K.; Sieval, A. B.; Fleer, G. J.; Stuart, M. A. C. Polyacrylic acid brushes: Surface pressure and salt-induced swelling. Langmuir 2000, 16, 8324-8333.

(39) Willott, J. D.; Murdoch, T. J.; Humphreys, B. A.; Edmondson, S.; Webber, G. B.; Wanless, E. J. Critical Salt Effects in the Swelling Behavior of a Weak Polybasic Brush. Langmuir 2014, 30, 1827-1836.

(40) Willott, J. D.; Murdoch, T. J.; Humphreys, B. A.; Edmondson, S.; Wanless, E. J.; Webber, G. B. Anion-Specific Effects on the Behavior of $\mathrm{pH}$-Sensitive Polybasic Brushes. Langmuir 2015, 31, 3707-3717.

(41) Lu, Y.; Zhuk, A.; Xu, L.; Liang, X.; Kharlampieva, E.; Sukhishvili, S. A. Tunable $\mathrm{pH}$ and temperature response of weak polyelectrolyte brushes: Role of hydrogen bonding and monomer hydrophobicity. Soft Matter 2013, 9, 5464-5472.

(42) Borozenko, O.; Ou, C.; Skene, W. G.; Giasson, S. Polystyreneblock-poly(acrylic acid) brushes grafted from silica surfaces: $\mathrm{PH}$ - and salt-dependent switching studies. Polym. Chem. 2014, 5, 2242-2252.

(43) Zhang, J.; Cai, H.; Tang, L.; Liu, G. Tuning the pH Response of Weak Polyelectrolyte Brushes with Specific Anion Effects. Langmuir 2018, 34, 12419-12427.

(44) Jia, H.; Wildes, A.; Titmuss, S. Structure of $\mathrm{pH}$-responsive polymer brushes grown at the gold-water interface: Dependence on grafting density and temperature. Macromolecules 2012, 45, 305-312.

(45) Geoghegan, M.; Ruiz-Perez, L.; Dang, C. C.; Parnell, A. J.; Martin, S. J.; Howse, J. R.; Jones, R. A. L.; Golestanian, R.; Topham, P. D.; Crook, C. J.; Ryan, A. J.; Sivia, D. S.; Webster, J. R. P.; Menelle, A. The $\mathrm{pH}$-induced swelling and collapse of a polybase brush synthesized by atom transfer radical polymerization. Soft Matter 2006, 2, 1076-1080.

(46) Schüwer, N.; Klok, H. A. Tuning the $\mathrm{pH}$ sensitivity of poly(methacrylic acid) brushes. Langmuir 2011, 27, 4789-4796.

(47) Willott, J. D.; Humphreys, B. A.; Murdoch, T. J.; Edmondson, S.; Webber, G. B.; Wanless, E. J. Hydrophobic effects within the dynamic $\mathrm{pH}$-response of polybasic tertiary amine methacrylate brushes. Phys. Chem. Chem. Phys. 2015, 17, 3880-3890.

(48) Cheesman, B. T.; Smith, E. G.; Murdoch, T. J.; Guibert, C.; Webber, G. B.; Edmondson, S.; Wanless, E. J. Polyelectrolyte brush $\mathrm{pH}$-response at the silica-aqueous solution interface: a kinetic and equilibrium investigation. Phys. Chem. Chem. Phys. 2013, 15, 1450214510 .

(49) Currie, E. P. K.; Wagemaker, M.; Stuart, M. A. C.; Van Well, A. A. Structure of grafted polymers, investigated with neutron reflectometry. Phys. B 2000, 283, 17-21.

(50) Field, J. B.; Toprakcioglu, C.; Ball, R. C.; Stanley, H. B.; Dai, L.; Barford, W.; Penfold, J.; Smith, G.; Hamilton, W. Determination of End-Adsorbed Polymer Density Profiles by Neutron Reflectometry. Macromolecules 1992, 25, 434-439.

(51) Cosgrove, T.; Heath, T. G.; Phipps, J. S.; Richardson, R. M. Neutron Reflectivity Studies of Polymers Adsorbed on Mica from Solution. Macromolecules 1991, 24, 94-98.

(52) Zhulina, E. B.; Borisov, O. V. Structure and interaction of weakly charged polyelectrolyte brushes: Self-consistent field theory. $J$. Chem. Phys. 1997, 107 (15), 5952-5967.

(53) Chen, H.; Zajac, R.; Chakrabarti, A. Conformational properties of polyelectrolyte brushes: A Monte Carlo and self-consistent-field study. J. Chem. Phys. 1996, 104, 1579-1588.

(54) de Vos, W. M.; Leermakers, F. A. M. Modeling the structure of a polydisperse polymer brush. Polymer 2009, 50, 305-316.

(55) Murdoch, T. J.; Humphreys, B. A.; Johnson, E.; Prescott, S. W.; Nelson, A.; Wanless, E. J.; Webber, G. B. The role of copolymer composition on the specific ion and thermoresponse of ethylene glycol-based brushes. Polymer 2018, 138, 229-241.

(56) Nap, R. J.; Tagliazucchi, M.; Szleifer, I. Born energy, acid-base equilibrium, structure and interactions of end-grafted weak polyelectrolyte layers. J. Chem. Phys. 2014, 140, 024910.
(57) Gong, P.; Wu, T.; Genzer, J.; Szleifer, I. Behavior of SurfaceAnchored Poly(acrylic acid) Brushes with Grafting Density Gradients on Solid Substrates: 2. Macromolecules 2007, 40, 8765-8773.

(58) Voinova, M. V.; Rodahl, M.; Jonson, M.; Kasemo, B. Viscoelastic acoustic response of layered polymer films at fluid-solid interfaces: Continuum mechanics approach. Phys. Scr. 1999, 59, 391396.

(59) Fang, J.; Zhu, T.; Sheng, J.; Jiang, Z.; Ma, Y. Thickness dependent effective viscosity of a polymer solution near an interface probed by a quartz crystal microbalance with dissipation method. Sci. Rep. 2015, 5, 1-7.

(60) Dunér, G.; Thormann, E.; Dedinaite, A. Quartz Crystal Microbalance with Dissipation (QCM-D) studies of the viscoelastic response from a continuously growing grafted polyelectrolyte layer. $J$. Colloid Interface Sci. 2013, 408, 229-234.

(61) Majoinen, J.; Walther, A.; McKee, J. R.; Kontturi, E.; Aseyev, V.; Malho, J. M.; Ruokolainen, J.; Ikkala, O. Polyelectrolyte brushes grafted from cellulose nanocrystals using $\mathrm{Cu}$-mediated surfaceinitiated controlled radical polymerization. Biomacromolecules 2011 , 12, 2997-3006.

(62) Ogieglo, W.; Wormeester, H.; Eichhorn, K. J.; Wessling, M.; Benes, N. E. In situ ellipsometry studies on swelling of thin polymer films: A review. Prog. Polym. Sci. 2015, 42, 42-78.

(63) Ramos, J. J. I.; Moya, S. E. Water content of hydrated polymer brushes measured by an in situ combination of a quartz crystal microbalance with dissipation monitoring and spectroscopic ellipsometry. Macromol. Rapid Commun. 2011, 32, 1972-1978.

(64) Li, X.; Liu, L.; Zhao, J.; Tan, J. Optical properties of sodium chloride solution within the spectral range from 300 to $2500 \mathrm{~nm}$ at room temperature. Appl. Spectrosc. 2015, 69, 635-640.

(65) Tan, C. Y.; Huang, Y. X. Dependence of Refractive Index on Concentration and Temperature in Electrolyte Solution, Polar Solution, Nonpolar Solution, and Protein Solution. J. Chem. Eng. Data 2015, 60, 2827-2833.

(66) Rodahl, M.; Kasemo, B. On the measurement of thin liquid overlayers with the quartz-crystal microbalance. International Conference on Solid-State Sensors and Actuators, and Eurosensors IX, Proceedings 1995, 2, 743-746.

(67) Rodahl, M.; Höök, F.; Fredriksson, C.; Keller, C. A.; Krozer, A.; Brzezinski, P.; Voinova, M.; Kasemo, B. Simultaneous frequency and dissipation factor QCM measurements of biomolecular adsorption and cell adhesion. Faraday Discuss. 1997, 107, 229-246.

(68) Höök, F.; Kasemo, B.; Nylander, T.; Fant, C.; Sott, K.; Elwing, $\mathrm{H}$. Variations in coupled water, viscoelastic properties, and film thickness of a Mefp-1 protein film during adsorption and crosslinking: A quartz crystal microbalance with dissipation monitoring, ellipsometry, and surface plasmon resonance study. Anal. Chem. 2001, 73, 5796-5804.

(69) Voinova, M. V.; Rodahl, M.; Jonson, M.; Kasemo, B. Viscoelastic Acoustic Response of Layered Polymer Films at FluidSolid Interfaces: Continuum Mechanics Approach. Phys. Scr. 1999, 59, 391-396.

(70) Keiji Kanazawa, K; Gordon, J. G The oscillation frequency of a quartz resonator in contact with liquid. Anal. Chim. Acta 1985, 175, $99-105$.

(71) Kasputis, T.; Koenig, M.; Schmidt, D.; Sekora, D.; Rodenhausen, K. B.; Eichhorn, K. J.; Uhlmann, P.; Schubert, E.; Pannier, A. K.; Schubert, M.; Stamm, M. Slanted columnar thin films prepared by glancing angle deposition functionalized with polyacrylic acid polymer brushes. J. Phys. Chem. C 2013, 117, 13971-13980.

(72) Kurosawa, S.; Aizawa, H.; Talib, Z. A.; Atthoff, B.; Hilborn, J. Synthesis of tethered-polymer brush by atom transfer radical polymerization from a plasma-polymerized-film-coated quartz crystal microbalance and its application for immunosensors. Biosens. Bioelectron. 2004, 20, 1165-1176.

(73) Borisova, O. V.; Billon, L.; Richter, R. P.; Reimhult, E.; Borisov, O. V. PH- and Electro-Responsive Properties of Poly(acrylic acid) and Poly(acrylic acid)-block-poly(acrylic acid-grad-styrene) Brushes 
Studied by Quartz Crystal Microbalance with Dissipation Monitoring. Langmuir 2015, 31, 7684-7694.

(74) Delcroix, M. F.; Demoustier-Champagne, S.; Dupont-Gillain, C. C. Quartz crystal microbalance study of ionic strength and $\mathrm{pH}$ dependent polymer conformation and protein adsorption/desorption on PAA, PEO, and mixed PEO/PAA brushes. Langmuir 2014, 30, $268-277$.

(75) Liu, G.; Zhang, G. Periodic swelling and collapse of polyelectrolyte brushes driven by chemical oscillation. J. Phys. Chem. B 2008, 112, 10137-10141.

(76) Cui, J.; Azzaroni, O.; del Campo, A. Polymer Brushes with Phototriggered and Phototunable Swelling and $\mathrm{pH}$ Response. Macromol. Rapid Commun. 2011, 32, 1699-1703.

(77) Prabhu, V. M.; Vogt, B. D.; Wu, W.; Douglas, J. F.; Lin, E. K.; Satija, S. K.; Goldfarb, D. L.; Ito, H. Direct measurement of the counterion distribution within swollen polyelectrolyte films. Langmuir 2005, 21, 6647-6650.

(78) Muller, F.; Fontaine, P.; Delsanti, M.; Belloni, L.; Yang, J.; Chen, Y. J.; Mays, J. W.; Lesieur, P.; Tirrell, M.; Guenoun, P. Counterion distribution in a spherical charged sparse brush. Eur. Phys. J. E: Soft Matter Biol. Phys. 2001, 6, 109-115.

(79) Tanchak, O. M.; Yager, K. G.; Fritzsche, H.; Harroun, T.; Katsaras, J.; Barrett, C. J. Ion distribution in multilayers of weak polyelectrolytes: A neutron reflectometry study. J. Chem. Phys. 2008, 129, 084901. 